\title{
Long term benefits of rehabilitation at home on quality of life and exercise tolerance in patients with chronic obstructive pulmonary disease
}

\author{
P J Wijkstra, E M TenVergert, R van Altena, V Otten, J Kraan, D S Postma, \\ G H Koëter
}

\begin{abstract}
Background - Pulmonary rehabilitation has been shown to have short term subjective and objective benefits for patients with chronic obstructive pulmonary disease (COPD). However, appropriately controlled studies have not previously been performed, nor have the benefits of different types of continuation programme for rehabilitation been investigated. Both these problems have been addressed in a single study of the long term effects of once monthly physiotherapy versus once weekly physiotherapy at home after a comprehensive home rehabilitation programme on quality of life and exercise tolerance in patients with COPD.

Methods - Thirty six patients with severe airways obstruction (mean (SD) forced expiratory volume in one second $\left(F^{2} V_{1}\right)$

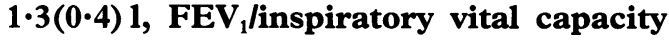
(IVC) $37 \cdot 2(7 \cdot 9) \%$ ) were studied. Twenty three patients followed a rehabilitation programme at home for 18 months consisting of physiotherapy and supervision by a nurse and general practitioner. During the first three months all 23 patients visited the physiotherapist twice a week for a 0.5 hour session. Thereafter, 11 patients (group A) received a session of physiotherapy once weekly while 12 patients (group B) received a session of physiotherapy once a month. The control group C (13 patients) received no rehabilitation at all. Quality of life was assessed by the Chronic Respiratory Questionnaire, exercise tolerance by the six minute walking distance, and lung function by FEV ${ }_{1}$ and IVC. Outcome measures were assessed at baseline and at three, six, 12, and 18 months.
\end{abstract}

Results - Long term improvements in quality of life were found in patients in groups $A$ and $B$, but not in those in group $C$ compared with baseline, but these only reached significance in group $B$ at all time points. Patients in group $B$ had a higher quality of life than those in group $C$ only at three and 12 months. There was a decrease in both six minute walking distance (at 12 and 18 months) and IVC (at three,
12, and 18 months) in patients in group $C$ compared with the baseline measurement. Between groups analysis showed no differences for six minute walking distance, $\mathrm{FEV}_{1}$, and IVC.

Conclusions - This study is the first to show that rehabilitation at home for three months followed by once monthly physiotherapy sessions improves quality of life over 18 months. The change in quality of life was not associated with a change in exercise tolerance.

(Thorax 1995;50:824-828)

Keywords: home rehabilitation, quality of life, exercise tolerance, chronic obstructive pulmonary disease.

Rehabilitation of patients with chronic obstructive pulmonary disease (COPD) improves both quality of life and exercise tolerance. ${ }^{1-8}$ Most studies have had a short follow up of up to six months ${ }^{124-68}$ and were carried out in a clinical setting. ${ }^{3-68}$ Quality of life has not frequently been assessed by a valid questionnaire, and only one study ${ }^{3}$ showed both an improved exercise tolerance and an improved quality of life after one year. This study assessed quality of life by the Chronic Respiratory Questionnaire, which was shown to be valid and responsive ${ }^{910}$; however, a control group was not included. ${ }^{3}$

Although rehabilitation improves both exercise tolerance and quality of life in COPD, it is not known whether these improvements are related to each other. The weak correlation between quality of life and the six minute walking distance $\mathrm{e}^{11-13}$ in patients with COPD suggests that these parameters measure different aspects of health.

So far there has been no conclusive evidence that rehabilitation improves quality of life and exercise tolerance, as most investigations have not included a control group. We have developed a rehabilitation programme in the home for a period of 18 months and included a control group. As the optimal frequency of follow up of physiotherapy sessions after a more intensive start is not known, we compared two different types of follow up of physiotherapy 
after a 12 week rehabilitation programme that is, one group received a monthly session of physiotherapy while the other group received a weekly session. We investigated their long term effects on quality of life and exercise tolerance after three, six, 12 , and 18 months of rehabilitation. In addition we examined the relation between the change in quality of life and the change in exercise tolerance.

\section{Methods \\ PATIENTS}

Forty five patients with defined COPD according to the American Thoracic Society criteria $^{14}$ were studied. Entry criteria were: (1) postbronchodilator forced expiratory volume in one second $\left(\mathrm{FEV}_{1}\right)<60 \%$ predicted, and (2) postbronchodilator $\mathrm{FEV}_{1}$ /inspiratory vital capacity (IVC) $<50 \%$ (after two inhalations of $40 \mu \mathrm{g}$ ipratropium bromide). All patients showed severe airways obstruction (mean $\mathrm{FEV}_{1}$ $44 \%$ predicted, mean $\mathrm{FEV}_{1} / \mathrm{IVC} 37 \%$ ) and little reversibility (mean increase in $\mathrm{FEV}_{1}$ of $0.151,5 \%$ of predicted $\mathrm{FEV}_{1}$ ). They were admitted to the hospital for two days in a stable condition with optimal drug management. Patients with evidence of ischaemic heart disease, intermittent claudication, musculoskeletal disorders, or other disabling diseases were excluded. The study was approved by the medical ethics committee of the University Hospital of Groningen and all patients gave informed consent.

\section{STUDY DESIGN}

Stratified randomisation was used to achieve approximate balance of important characteristics in the groups, ${ }^{15}$ including their $\mathrm{FEV}_{1}$ ( $<$ or $\geqslant 45 \%$ predicted), the maximal workload of their cycle ergometer test $(<$ or $\geqslant 70 \mathrm{~W})$, and their limiting factor to exercise (ventilatory limitation or non-ventilatory limitation). ${ }^{16}$ They were randomly allocated to one of three groups, each of 15 patients. Two groups (A and $B$ ) started a rehabilitation programme for 18 months, while the third group (C) received no rehabilitation at all. Patients were supervised by a multidisciplinary team during their rehabilitation programme at home comprising a pulmonary physician, physiotherapist, nurse, and general practitioner. A coordinating doctor (PJW) visited the participating professionals before the study to instruct them on the home rehabilitation programme. During the first 12 weeks both rehabilitation groups (A and B) visited their local physiotherapist twice a week for a session of 0.5 hours, and the patients were also coached once a month by both a general practitioner and a local nurse. Thereafter, group A visited the physiotherapist for a weekly 0.5 hour session while group B had a monthly session of 0.5 hours. At baseline, after three months, six months, 12 months, and 18 months the following measurements were carried out: (1) lung function, (2) quality of life, (3) six minute walking distance.

\section{REHABILITATION PROGRAMME}

The physiotherapy programme comprised sessions of 0.5 hours during which the patients were trained in different kinds of exercises. These training sessions, which took place in the house of the local physiotherapist, included relaxation exercises, breathing retraining, upper limb training, target flow inspiratory muscle training, and exercise training on a home trainer. Relaxation exercises were carried out using progressive muscle relaxation. ${ }^{17}$ Breathing retraining consisted of education on COPD, pursed lip breathing, expiratory abdominal augmentation, and synchronisation of the movement of the thorax and abdomen. ${ }^{18}$ Upper limb training was carried out according to the principles of proprioceptive neuromuscular facilitation consisting of two exercises for each arm with the same weight and coordinated with breathing during exhalation. ${ }^{19}$ Inspiratory muscle training was with a Respirex (DHD Medical Products, New York, USA) and an added resistance. ${ }^{20}$ Exercise training was with a home trainer, ${ }^{21}$ which was a mechanically braked bicycle, of which the workload was adjusted to their Wmax baseline, and it had an odometer. The patients were instructed to keep their speed at 60 rotations per minute. They started exercise training for four minutes at $60 \%$ of their maximal workload (Wmax) achieved at baseline. The time span of daily training was gradually extended to 12 minutes and the workload to a maximum of $75 \%$ of the Wmax. The exercises were taught by the physiotherapist and practised during the entire rehabilitation period. Relaxation exercises and breathing retraining were performed on alternating days and inspiratory muscle training, upper limb training, and exercise training daily. Patients had to practise twice a day for an individualised protocol, for 0.5 hours the first three months and then once a day only for 0.5 hours.

The nurse visited the patients at home and provided information about pulmonary disease, various strategies for treatment, medication, how to cope with the disease, and the role of a rehabilitation programme in this strategy. The patient also made a monthly visit to the general practitioner who supervised the clinical status and maintenance treatment. All patients, including the control group, received a diary in which to enter the time spent on daily activities, while the patients in the rehabilitation groups also had to enter the time spent on exercises.

\section{OUTCOME MEASURES}

\section{Lung function}

Total lung capacity (TLC), residual volume (RV), $\mathrm{FEV}_{1}, \mathrm{IVC}$, and transfer factor for carbon monoxide (TLCO) were measured during the initial evaluation. Static lung volumes were determined using a constant volume body plethysmograph (Jaeger, Würzburg, Germany), $\mathrm{FEV}_{1}$ and IVC with a pneumotachograph (Jaeger, Würzburg, Germany), and TLco by the single breath method. After three, six, and 12 months only $\mathrm{FEV}_{1}$ and IVC were measured. After 18 months all lung function tests were repeated. Predicted values were derived from the ECCS. ${ }^{22}$ 
Table 1 Mean (SD) baseline characteristics

\begin{tabular}{|c|c|c|c|}
\hline & $\begin{array}{l}\text { Group } A \\
(n=11)\end{array}$ & $\begin{array}{l}\text { Group B } \\
(n=12)\end{array}$ & $\begin{array}{l}\text { Group } C \\
(n=13)\end{array}$ \\
\hline $\mathrm{M}: \mathrm{F}$ & $8: 3$ & $10: 2$ & $12: 1$ \\
\hline Age (years) & $62 \cdot 3(5 \cdot 1)$ & $64 \cdot 0(6 \cdot 2)$ & $61.9(3.6)$ \\
\hline $\mathrm{FEV}, \mathrm{b}(\mathrm{l})$ & $1.2(0.3)$ & $1.2(0.4)$ & $1 \cdot 2(0 \cdot 3)$ \\
\hline FEV 1 a (l) & $1.3(0.4)$ & $1.4(0.4)$ & $1.3(0.3)$ \\
\hline $\mathrm{FEV}_{1}$ (\%pred) & $43 \cdot 2(11 \cdot 3)$ & $45 \cdot 3(12 \cdot 3)$ & $42 \cdot 9(8 \cdot 7)$ \\
\hline $\mathrm{FEV}_{1} / \mathrm{IVC}$ & $39.8(9 \cdot 6)$ & $37 \cdot 7(8 \cdot 3)$ & $35 \cdot 1(6 \cdot 6)$ \\
\hline TLC (\%pred) & $113.2(15.9)$ & $119 \cdot 5(13 \cdot 3)$ & $115.6(11.6)$ \\
\hline RV/TLC (\%pred) & $149.1(18.6)$ & $145 \cdot 4(24 \cdot 3)$ & $136.5(18.3)$ \\
\hline TLCo (\%pred) & $74 \cdot 4(17 \cdot 1)$ & $68.9(31.9)$ & $78.9(20.8)$ \\
\hline
\end{tabular}

$\mathrm{FEV}, \mathrm{b}=$ forced expiratory volume in one second before bronchodilation with two inhalations of $40 \mu \mathrm{g}$ ipratropium bromide; $\mathrm{FEV}_{1} \mathrm{a}=\mathrm{FEV}_{1}$ after bronchodilation; $\mathrm{FEV}_{1} / \mathrm{IVC}^{2}=\mathrm{FEV}_{1}$ expressed as a percentage of the slow inspiratory vital capacity; TLC = total lung capacity; $R V=$ residual as a percentage of the slow inspiratory vital capacity;
volume; TLCO $=$ transfer factor for carbon monoxide.

\section{Quality of life}

Quality of life was assessed by the Chronic Respiratory Questionnaire (CRQ) of Guyatt et $a l^{9}$ which was translated into Dutch. The CRQ is divided into four dimensions (dyspnoea, fatigue, emotion, and mastery) and measures both physical and emotional function. Physical function was investigated by five items relating to the dimension dyspnoea and by four items relating to the dimension fatigue. Assessment of emotional function, corresponding to the dimensions emotion and mastery, included questions about frustration, depression, anxiety, panic, and fear of dyspnoea. Patients were asked to rate their physical and emotional function on a seven point scale, a higher score representing better function. During the administration of the test patients were told their answer of the previous period, as advocated by Guyatt et al. ${ }^{23}$ In a previous study we showed that the dimensions fatigue, emotion, and mastery had a high internal consistency reliability and a high test retest reliability. Moreover, the validity of the CRQ was satisfactory. The dimension dyspnoea showed a low reliability and a low validity. ${ }^{24}$ As a consequence we restricted ourselves to the measurement of the dimensions fatigue, emotion, and mastery. The scores on the three dimensions were added in order to obtain a sum score for quality of life in each patient.

\section{Six minute walking distance}

During this test the patients walked indoors along a corridor of $42 \mathrm{~m}$ as far as possible during six minutes ${ }^{25}$ without encouragement. They had two training sessions at every time

Table 2 Mean (SD) quality of life data

\begin{tabular}{|c|c|c|c|c|c|}
\hline & Baseline & 3 months & 6 months & 12 months & 18 months \\
\hline $\begin{array}{l}\text { Group A } \\
\text { n } \\
\text { Fatigue } \\
\text { Emotion } \\
\text { Mastery }\end{array}$ & $\begin{array}{l}11 \\
16 \cdot 4(5 \cdot 4) \\
35 \cdot 4(7 \cdot 3) \\
20 \cdot 4(4 \cdot 0)\end{array}$ & $\begin{array}{l}11 \\
18 \cdot 7(6 \cdot 5) \\
37 \cdot 6(7 \cdot 2) \\
22 \cdot 0(4 \cdot 6)\end{array}$ & $\begin{array}{l}11 \\
19 \cdot 1(6 \cdot 8) \\
37 \cdot 7(7 \cdot 4) \\
22 \cdot 2(4 \cdot 8)\end{array}$ & $\begin{array}{l}11 \\
17.8(5 \cdot 9) \\
37.0(7 \cdot 1) \\
21.9(4 \cdot 7)\end{array}$ & $\begin{array}{l}10 \\
17 \cdot 4(6 \cdot 1) \\
37 \cdot 0(7 \cdot 9) \\
22 \cdot 2(4 \cdot 6)\end{array}$ \\
\hline $\begin{array}{l}\text { Group B } \\
\text { n } \\
\text { Fatigue } \\
\text { Emotion } \\
\text { Mastery }\end{array}$ & $\begin{array}{l}12 \\
17 \cdot 8(4 \cdot 7) \\
36 \cdot 6(6 \cdot 8) \\
21 \cdot 8(4 \cdot 9)\end{array}$ & $\begin{array}{l}12 \\
21 \cdot 7(3 \cdot 0) \dagger \\
41 \cdot 1(6 \cdot 2) \dagger \ddagger \\
24 \cdot 5(3 \cdot 7)^{*}\end{array}$ & $\begin{array}{l}12 \\
21 \cdot 8(3 \cdot 9)^{*} \\
41 \cdot 6(7 \cdot 0)^{*} \\
24 \cdot 7(3 \cdot 9)^{*}\end{array}$ & $\begin{array}{l}12 \\
21 \cdot 7(3.9) \dagger \ddagger \\
41 \cdot 0(7 \cdot 2)^{*} \ddagger \\
24 \cdot 8(3 \cdot 9) \dagger \ddagger\end{array}$ & $\begin{array}{l}11 \\
20.9(3.9)^{*} \\
38.6(7.8) \\
24 \cdot 1(4.3)^{*} \ddagger\end{array}$ \\
\hline $\begin{array}{l}\text { Group C } \\
\text { n } \\
\text { Fatigue } \\
\text { Emotion } \\
\text { Mastery }\end{array}$ & $\begin{array}{l}13 \\
16 \cdot 2(4 \cdot 1) \\
33 \cdot 5(6 \cdot 6) \\
20 \cdot 4(3 \cdot 9)\end{array}$ & $\begin{array}{l}13 \\
17 \cdot 4(3 \cdot 5) \\
34 \cdot 0(6 \cdot 1) \\
20 \cdot 3(4 \cdot 1)\end{array}$ & $\begin{array}{l}13 \\
18.0(3.5) \\
34.4(7 \cdot 1) \\
20.9(3 \cdot 4)\end{array}$ & $\begin{array}{l}13 \\
17.5(3.0) \\
33.4(6.9) \\
20.2(3.3)\end{array}$ & $\begin{array}{l}12 \\
17.7(3.4) \\
34.9(6.3) \\
20.6(3.0)\end{array}$ \\
\hline
\end{tabular}

${ }^{*} \mathrm{p}<0.05, \dagger \mathrm{p}<0.01$ compared with baseline; $\neq p<0.05$ compared with control group $\mathrm{C}$.

Fatigue, emotion, and mastery are dimensions of the Chronic Respiratory Questionnaire (CRQ). point to become familiar with the test. ${ }^{25}$ The last test at each time point was used in our analysis.

\section{STATISTICAL ANALYSIS}

The Kolmogorov-Smirnov test was used to compare distributions of the items with standard normal distributions. Analysis of variance for repeated measures and Scheffé's post hoc comparisons test between groups were applied for multiple comparisons between the three groups. Analysis of variance for repeated measures and Student's paired $t$ test were used for within groups comparisons. Significance level was set at $\mathrm{p}<0 \cdot 05$.

\section{Results}

Twelve of the 45 patients withdrew from the programme. Nine withdrew during the first 12 months, four from group A (one patient died from bronchial carcinoma, one lacked the motivation to continue, one was not able to face the tests, and one developed a cerebral tumour), three from group B (one died following a cardiac arrest, one developed arthritis, and one stopped because of personal problems), and two from group $\mathrm{C}$ (one died following a cardiac arrest and the other was unable to face the tests). Between 12 and 18 months after the start three patients dropped out; two died (one in group A with cardiac failure and one in group B with cardiac arrest), and one patient withdrew from group $\mathrm{C}$ because of a nasopharyngeal carcinoma. Thus, 36 patients were included in the analysis of the first 12 months: 11 in group A, 12 in group B, and 13 in group C. At 18 months 33 patients were available for analysis: 10 in group $A, 11$ in group B, and 12 in group C. At baseline, lung function, quality of life, and six minute walking distance did not differ significantly between the patients who dropped out and those who completed the study.

\section{LUNG FUNCTION}

At baseline there were no significant differences in lung function between the three groups (table 1 ). Analyses within the groups showed a significant $(p<0.05)$ decrease in $\mathrm{FEV}_{1}$ in group $\mathrm{B}$ at three months compared with the baseline value, while the IVC in group $C$ decreased significantly at three, 12 , and 18 months compared with the baseline. The $\mathrm{FEV}_{1}$ and IVC were not significantly different between the three groups at any time point.

\section{QUALITY OF LIFE}

The baseline data showed no significant differences between the three groups in the scores of the dimensions fatigue, emotion, and mastery (table 2). Only group B had significantly higher scores for all dimensions at all time points compared with the baseline values. In addition, the sum score for quality of life in both groups $A$ and $B$ was higher at all time points compared 


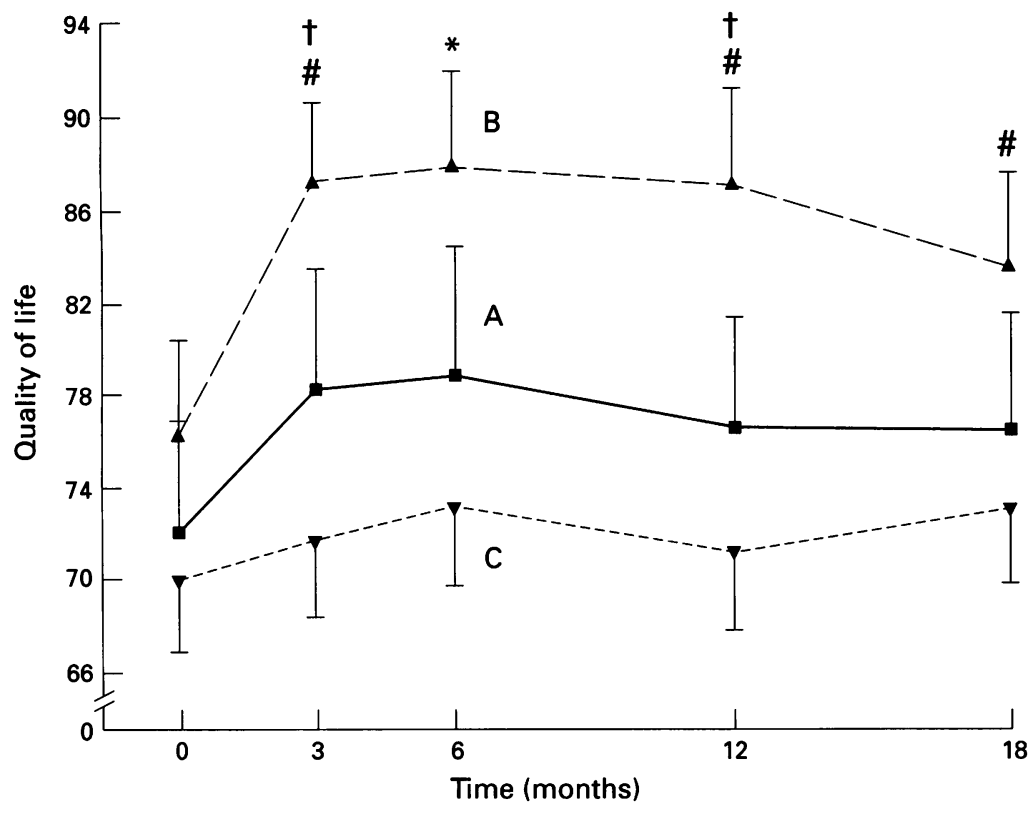

Figure 1 Quality of life (sum score). - - group $A$ (rehabilitation group follow up once $a$ week; during the first 12 months $n=11$, at 18 months $n=10) ;---=$ group $B$ (rehabilitation group follow up once a month; during the first 12 months $n=12$, at 18 months $n=11$ ); $\ldots=$ group $C$ (control group; during the first 12 months $n=13$, at 18 months $n=12) . * p<0.05$, \# $p<0.01$ compared with baseline; $\dagger p<0.05$ compared with control group $C$.

with their baseline value, and reached significance $(p<0.05)$ in only group $B$ at all time points (fig 1). There were significant improvements for all dimensions in group B compared with control group $C$ at 12 months, while the sum score of quality of life in group B was significantly higher than group $\mathrm{C}$ at three and 12 months. The differences in the quality of life sum scores between groups $\mathrm{A}$ and $\mathrm{B}$ and between groups $\mathrm{A}$ and $\mathrm{C}$ were not significant at any time point.

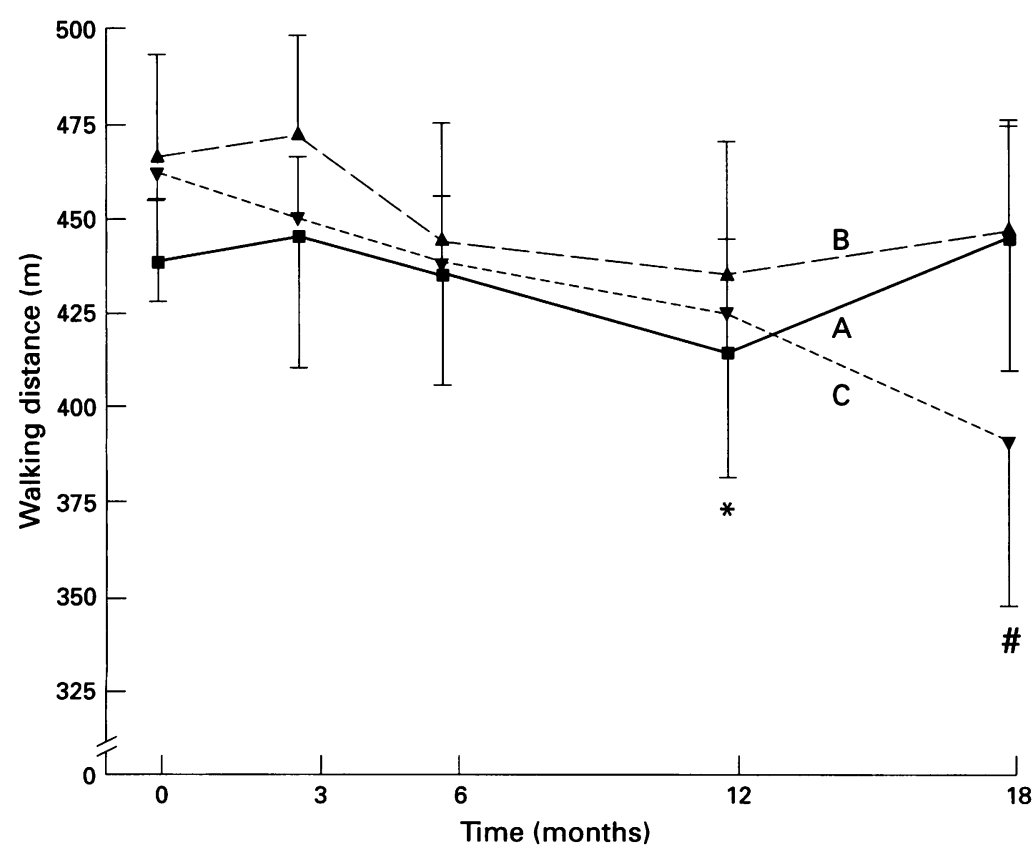

Figure 2 Six minute walking distance. $-=$ group $A$ (rehabilitation group follow up once a week; during the first 12 months $n=11$, at 18 months $n=10) ;--=$ group $B$ (rehabilitation group follow up once a month; during the first 12 months $n=12$, at 18 months $n=11$ ); ... = group $C$ (control group; during the first 12 months $n=13$, at 18 months $n=12$ ). * $p<0.05$, \# $p<0.01$ compared with baseline.
SIX MINUTE WALKING DISTANCE

The six minute walking distance of group C decreased significantly at 12 and 18 months compared with the baseline value, while no changes were seen in groups A and B (fig 2). The six minute walking distance was similar for the three groups at all time points.

\section{Discussion}

This study is the first to show that rehabilitation at home, continued by monthly physiotherapy sessions, was sufficient to sustain an initially improved quality of life over 18 months. The change in quality of life was not associated with a change in exercise tolerance.

Both rehabilitation groups (A and B) showed improvements in their quality of life compared with the baseline, being significant in group B at all time points. Moreover, group B showed a significantly improved quality of life at three and 12 months compared with the control group. Guyatt et $a l^{4}$ considered that an improvement of at least four points in the total quality of life score, consisting of four dimensions, is necessary to allow a patient subjective improvement in quality of life. Thus, in group $B$ the mean overall increase at 18 months of eight points from baseline in the quality of life score, consisting of only three dimensions, is clinically relevant. Although there was no significantly higher quality of life score in group A compared with group $C$, we suggest that the mean increase in the quality of life score of at least four points in group $A$ at all time points compared with baseline is clinically relevant. In contrast, group $\mathrm{C}$ did not show an increase of more than four points compared with the baseline values. Furthermore, Guyatt et $a l^{4}$ showed that the initial improvement in quality of life was sustained in only 11 of 24 patients $(45 \%)$ at six months after an inpatient rehabilitation programme of 4-6 weeks, and concluded that initial benefits cannot be sustained without further supervision. ${ }^{4}$ We have shown that initial improvement ( $\geqslant 4$ points) in quality of life can be sustained for 18 months in nine out of 12 patients (75\%) by physiotherapy given once a month.

Group A showed less improvement in quality of life than group B. A possible explanation for the difference between the groups may be the fact that patients in group B performed more exercise at home, while the patients in group A relied more on their weekly physiotherapy sessions. However, the diaries of both groups did not show much difference in the frequency of daily training. Because once monthly physiotherapy is cheaper and more convenient for the patients than weekly physiotherapy, we suggest that physiotherapy should be performed once a month.

Our findings differ from those of another study $^{3}$ which measured the outcome approximately 11 months (range 3-21 months) after a six week outpatient rehabilitation programme. No changes were seen in quality of life, assessed by the CRQ, between patients who chose to receive weekly exercise maintenance after rehabilitation and those who did 
not. They concluded that there was no need for follow up treatment after an initial rehabilitation programme. However, there may be bias in this as it is not clear whether the follow up time in both groups was the same, there was a higher dropout rate in those who did not receive exercise maintenance, and patients had not been randomly allocated. ${ }^{3}$

Unlike other studies, ${ }^{37}$ we did not find an increased tolerance to exercise after rehabilitation. The difference in exercise tolerance between our study and others may be explained by the facts that (a) the studies by Vale $e t a l^{\beta}$ and Sinclair and Ingram ${ }^{7}$ used the 12 minute walking distance which is probably more sensitive to change than the six minute walking distance ${ }^{2526}$; (b) the increase in 12 minute walking distance in the study by Vale et $a l^{\beta}$ may be a training effect as patients did not carry out practice tests before baseline values were obtained and it has previously been advocated that at least two training tests should be carried out to exclude this initial training effect ${ }^{25}$; (c) the large improvement (24\%) in 12 minute walking distance in the study of Sinclair and coworkers ${ }^{7}$ may be explained by daily training using the 12 minute walking distance since it is known that the greatest benefit in exercise tests is assessed by specific training $^{25}$; and (d) our results may be influenced by the small number of patients in each group and the dropout rate.

The significant decrease in six minute walking distance and IVC in our control group at 12 and 18 months is surprising and was not found in the controlled study of Sinclair et al. ${ }^{7}$ However, their follow up period was shorter (11 months) and their "control" group also received an initial rehabilitation programme which may have increased their exercise tolerance. Although the patients in our rehabilitation groups, in contrast with the control group, visited their general practitioner once a month during the first three months, this was only to assess their clinical status. The maintenance treatment in all groups did not change during the 18 months and all patients received oral corticosteroids and antibiotics for an exacerbation in the standard way. There was no difference in the number of infective exacerbations during the rehabilitation period between the groups. We cannot explain the decrease in lung function and exercise tolerance in the control group.

We thank $\mathbf{R}$ Venema of the Lung Function Laboratory of Beatrixoord and Ms A Stegmeijer for their technical assistance in the performance of this study.

This study was supported by a grant from the Nederlands Astma Fonds (89.29) and the Foundation Astmabestrijding.
1 McGavin CR, Gupta SP, Lloyd EL, McHardy JR. Physical rehabilitation for chronic bronchitic: results of a controlled trial of exercises in the home. Thorax 1977;32:307-11.

2 Wijkstra PJ, van Altena R, Kraan J, Otten V, Postma DS Koëter GH. Quality of life in patients with chronic obstructive pulmonary disease improves after rehabilitation at home. Eur Respir f 1994;7:269-73.

3 Vale F, Reardon JZ, ZuWallack RL. The long-term benefits of outpatient pulmonary rehabilitation on exercise tolerance and quality of life. Chest 1993;103:42-5.

4 Guyatt GH, Berman LB, Townsend BA. Long-term outcome after respiratory rehabilitation. Can Med Assoc $\mathcal{F}$ 1987; 137:1089-95.

5 Emery CF, Leatherman NE, Burker EJ, MacIntyre NR. Psychological outcomes of a pulmonary rehabilitation proPsychological outcomes of a pult

6 Atkins CJ, Kaplan RM, Timms RM, Reinsch S, Lofback $K$. Behavioral exercise programs in the management of chronic obstructive pulmonary disease. $\mathcal{f}$ Consult Clin Psychol 1984;52:591-603.

7 Sinclair DJM, Ingram CG. Controlled trial of supervised exercise training in chronic bronchitis. BMF 1980;1:519 21.

8 Petty TL, Nett LM, Finigan MM, Brink GA, Corsello PR. A comprehensive care program for chronic airway obstruction. Ann Intern Med 1969;70:1109-20.

9 Guyatt GH, Berman LB, Townsend M, Pugsley SO, Chambers LW. A measure of quality of life for clinical trials in bers LW. A measure of quality of life for clinica

10 Guyatt G. Measuring health status in chronic airflow lim itation. Eur Respir f 1988;1:560-4.

11 Guyatt GH, Townsend M, Pugsley SO, Keller J, Singer J, Nognacli S. Measuring functional status in chronic lung disease: conclusions from a randomized control trial. Respir Med 1989;83:293-7.

12 Jones PW, Quirk FH, Baveystock CM, Littlejohns P. A selfcomplete measure of health status for chronic airflow limitation. Am Rev Respir Dis 1992;145:1321-7.

13 Wijkstra PJ, TenVergert EM, van der Mark ThW, Postma DS, van Altena R, Kraan J, et al. Relation of lung function, maximal inspiratory pressure, dyspnoea, and quality of life with exercise capacity in patients with chronic obstructive pulmonary disease. Thorax 1994;49:468-72.

14 Standards for the diagnosis and care of patients with chronic obstructive pulmonary disease (COPD) and asthma. An official statement of the American Thoracic Society. $A n$ Rev Respir Dis 1987;136:225-44.

15 Altman DG. Designing research. In: Altman DG, ed. Practical statistics for medical research. London: Chapman and Hall, 1991:88-9.

16 Folgering H, Dekhuijzen PNR, Cox N, van Herwaarden C. The rationale of pulmonary rehabilitation. Eur Respir Rev 1991;1:6,464-71.

17 Jerman A, Campbell Haggerty M. Relaxation and biofeedback: coping skills training. In: Casaburi R, Petty TL, eds. Principles and practice of pulmonary rehabilitation. Philadelphia: WB Saunders, 1993:366-81.

18 Casciari RJ, Firshter RD, Harrison A, Morrison JT, Blackburn C, Wilson AF. Effects of breathing retraining in burn C, Wilson AF. Effects of breathing

19 Ries AL, Ellis B, Hawkins RW. Upper extremity exercise training in chronic obstructive pulmonary disease. Chest 1988;93:688-92.

20 Dekhuijzen PNR, Folgering HTM, Van Herwaarden CLM Target-flow inspiratory muscle training during pulmonary rehabilitation in patients with COPD. Chest 1991;99:12833.

21 Allison JA, Samios R, Anderson SD. Evaluation of exercise training in patients with chronic airway obstruction. Phys Ther 1981;61:1273-7.

22 Quanjer PH, ed. Standardized lung function testing. Report of Working Party for Standardization of Lung Function Tests. European Community for Coal and Steel, LuxTests. European Community for Coal and Steel, Luxembourg.

23 Guyatt GH, Townsend M, Keller JL, Singer J. Should study subjects see their previous responses: data from a randomized control trial. $\mathscr{f}$ Clin Epidemiol 1989;42:913-20.

24 Wijkstra PJ, TenVergert EM, van Altena R, Otten V, Postm DS, Kraan J, et al. Reliability and validity of the Chronic Respiratory Questionnaire (CRQ). Thorax 1994;49:4657.

25 Butland RJA, Pang J, Gross ER, Woodcock AA, Geddes DM. Two-, six- and 12 minute walking tests in respiratory disease. Br 7 Dis Chest 1982;284:1607-8.

26 Bernstein ML, Despars JA, Singh NP, Avalos K, Stansbury $\mathrm{DW}$, Light RW. Reanalysis of the 12-minute walk in patients with chronic obstructive pulmonary disease. Chest patients with chronit 